\title{
Microsurgical anatomy of the anterior approach to the mesial temporal region
}

\author{
Eberval Gadelha Figueiredo ${ }^{1}$, Manoel Jacobsen Teixeira² \\ Division of Neurological Surgery University of São Paulo School of Medicine - São Paulo, SP, Brazil.
}

\begin{abstract}
Anterior approaches to the mesial temporal lobe are favored by its anatomy limited medially by the cerebral peduncle and laterally by the lateral temporal lobe. We have routinely used an anterior subfrontal approach to operate on mesial temporal lesions. In this paper, we describe its microsurgical anatomy and detail its clinical application. Surgical positioning, removal of the orbital rim, and drilling the sphenoid ridge are the main principles of this technique. Adequate positioning is crucial to displace the temporal lobe from the middle fossa to improve exposure. Removing the orbital rim ensures an ample range of movement for the surgical microscope, augments visualization, and improves surgical versatility. Finally, drilling the sphenoid ridge amplifies exposure near the area of interest, permitting increased visualization and manipulation.
\end{abstract}

\section{KEYWORDS}

Microsurgical, temporal lobe, surgical procedures minimally invasive.

\section{RESUMO}

Anatomia microcirúrgica do acesso anterior à região temporal mesial

Acessos ventrais ao lobo temporal são favorecidos pela própria anatomia do lobo temporal, limitado medialmente pelo pedúnculo cerebral. Os autores têm utilizado rotineiramente um acesso subfrontal anterior para operar lesões mesiais. Neste estudo, serão descritas a anatomia microcirúrgica e a aplicação clínica. Posicionamento, remoção do rebordo orbitário e drilagem da asa do osso esfenoide são fundamentais para garantir exposição cirúrgica satisfatória, versatilidade operatória e visualização adequada.

\section{PALAVRAS-CHAVE}

Microcirurgia, lobo temporal, procedimentos cirúrgicos minimamente invasivos.

\section{Introduction}

Anterior approaches to the mesial temporal lobe are favored by its anatomy limited medially by the cerebral peduncle and laterally by the lateral temporal lobe. We have routinely used an anterior subfrontal approach to operate on mesial temporal lesions. In this paper, we describe its microsurgical anatomy and detail its clinical application.

\section{Microsurgical technique and surgical anatomy}

The authors illustrate the technique operating on a patient with a mesial temporal cavernous malformation (Figure 1). A minisupraorbital craniotomy is performed..$^{1-9}$ The skin incision was similar to that used to perform an orbitozygomatic craniotomy. However, a supraciliar incision provides room for a similar cra- 
niotomy. ${ }^{1-4}$ The selection of the incision will depend upon the surgeon's preference. A burr hole was placed at the level of the frontozygomatic suture. The bone flap included the portion of the orbital rim lateral to the notch and extended 2.5 to $3.0 \mathrm{~cm}$ over the frontal bone along the craniocaudal axis (Figure 2).

After the sphenoid ridge is drilled, the dura mater is opened with its base directed toward the orbit. The basal cisterns are opened completely to expose the optic nerve, internal carotid artery (ICA), ICA bifurcation, anterior cerebral artery, and middle cerebral artery (MCA) and its temporal branches. The frontal lobe is retracted gently and the Sylvian fissure is split widely (Figure 3A). These maneuvers allow better, non-traumatic and less extensive frontal lobe retraction, widen the surgical corridor and improve the possibilities of working in multiple trajectories. The topography of the ICA, posterior cerebral artery (PCA), anterior choroidal artery, and third cranial nerve is inspected, and these structures are preserved.

The early branches of the first segment (M1) of the MCA are dissected, and the temporopolar, anterior temporal, and variable uncal arteries are identified. The uncus is dissected free from its attachments to the third cranial nerve and ICA. Next, the crural cistern is opened and the PCA was exposed. These maneuvers provided free access to the mobilized temporal lobe.

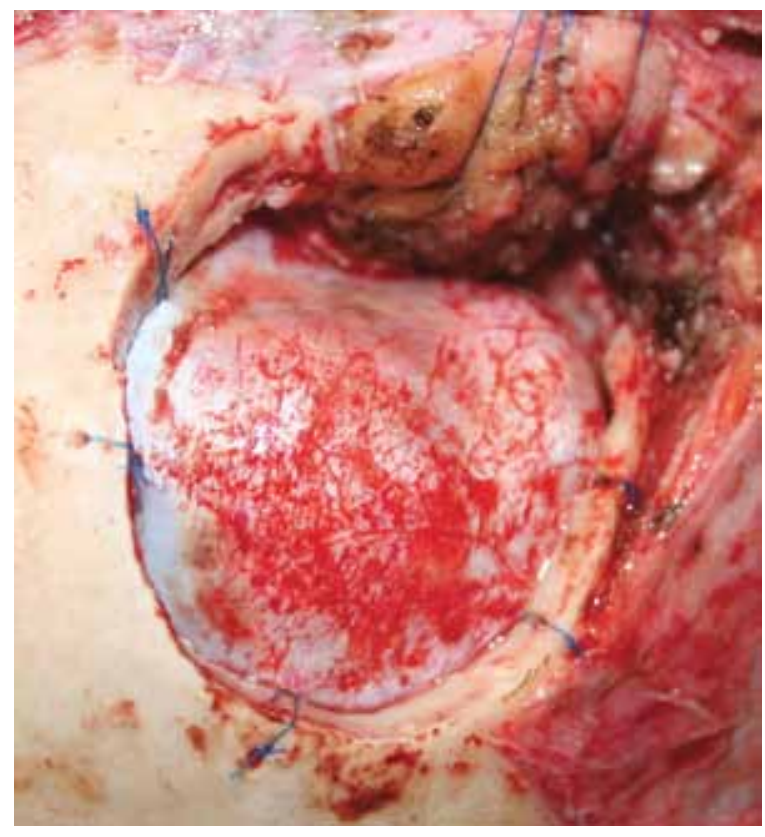

Figure 2 - A minisupraorbital approach with removal of the orbital rim has been performed.

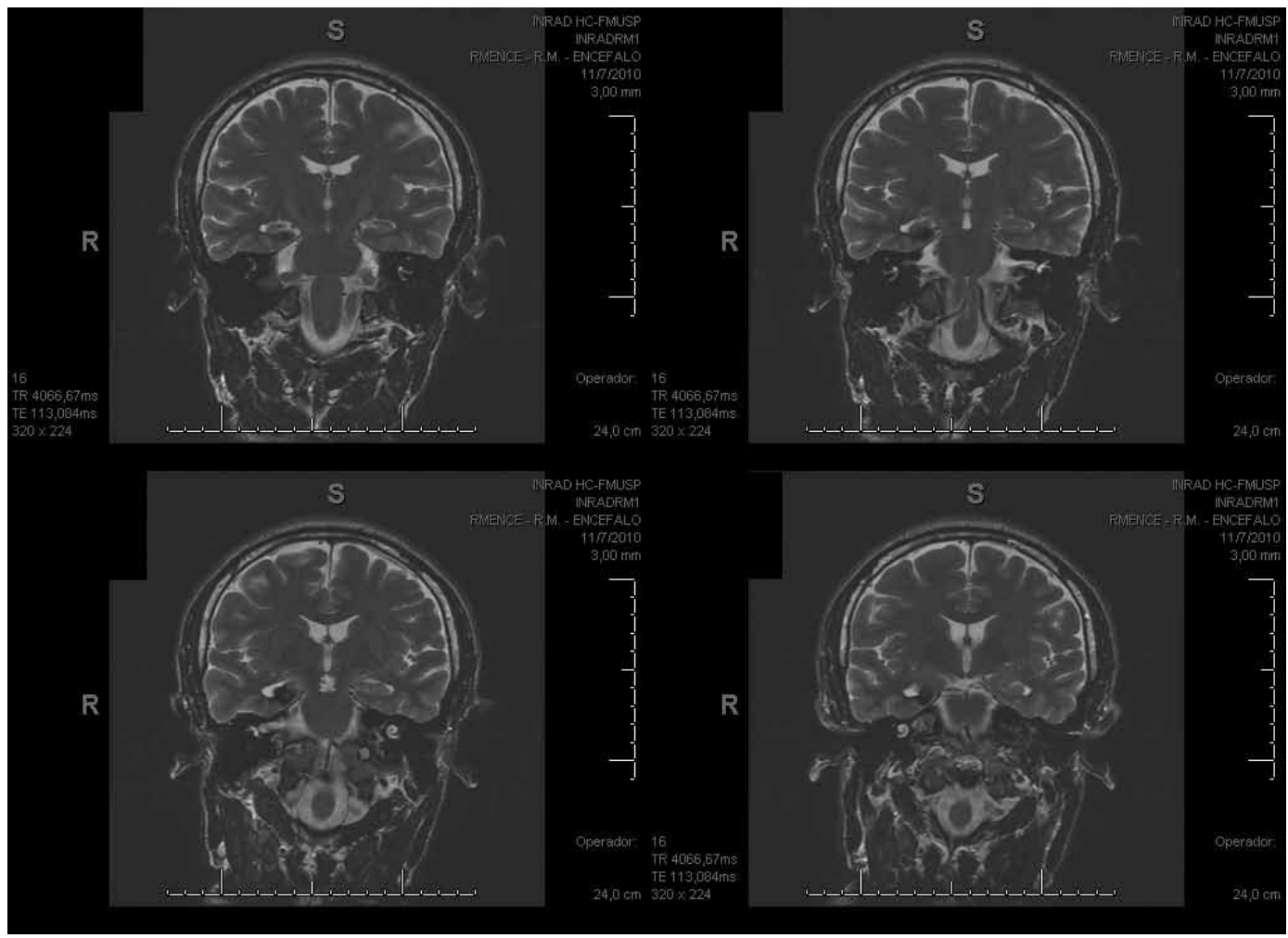

Figure 1 - MRI scan showing a mesial temporal lobe cavernous malformation. 
If the goal is surgical removal of the amygdala and hippocampus, the site of the primary cortical incision is located lateral and slightly superior to the uncus at the level of the rhinal incisure (Figure 3B). Its location corresponds to the projection of the temporal horn of the lateral ventricle and the head of the hippocampus over the ventral surface of the temporal lobe. The resection proceeded subpially to the temporal horn and head of the hippocampus (Figures 3B, C).
After these important landmarks are localized, the lateral (lateral wall of the temporal horn), medial (pia mater of the mesial temporal lobe and arachnoid membranes of the crural and ambient cisterns), and superior (roof of the temporal horn) limits of the resection were established. The dissection progressed subpially, medial to the lateral wall and inferior to the roof of the temporal horn. The hippocampus is identified and either resected en bloc or subpially along with the uncus up to
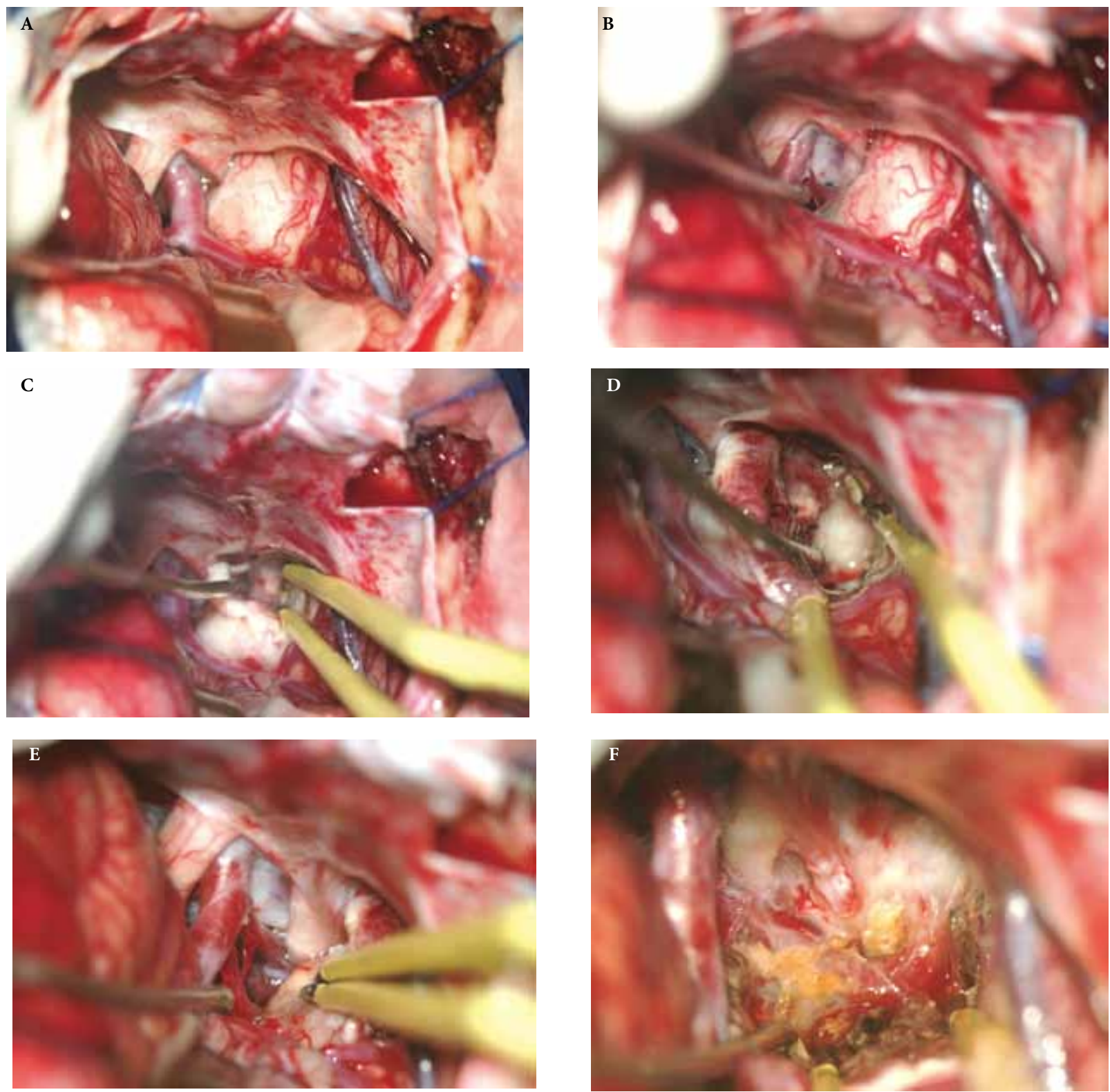

Figure 3 - Dura mater has been opened in a C-fashion. (A) Sylvian fissure has been split to expose ICA, optic nerve and M1 segment of MCA. (B) Uncus has been exposed and dissected from its adherences to the PComA and oculomotor nerve. (C) Resection of the mesial temporal lobe has been started subpially. (D) Floor of the middle fossa may be appreciated. (E) Mesial exposure has been improved and PcomA, AchA and PCA have been identified. (F) Mesial temporal lobe has been removed. ICA: internal carotid artery; MCA: middle cerebral artery; PcomA: posterior communicating artery; AchA: Anterior choroidal artery; PCA: posterior cerebral artery. 
the level of the posterior border of the cerebral peduncles and ambient cistern (Figures 3D, E). The remaining parahippocampal gyrus is removed to expose critical structures, such as the cerebral peduncles, third cranial nerve, optic tract, anterior choroidal artery, posterior communicating artery (PCoA), PCA, and basal vein beneath the pia and arachnoid membranes.

Additional resection of the posterior hippocampus may require further subpial dissection of the temporal lobe anterior to the temporal horn (Figure 3F). This step is also necessary to resect the superomedial portion of the amygdala, which was removed by continuing the dissection anterior, superior, and medial to the head of the hippocampus to reach the crural cistern. After this step, the optic tract could be identified at the roof of the crural cistern. The optic track served as a landmark to indicate appropriate and complete resection of the amygdala (Figures 3E, F).

At the end of the procedure, the floor of the middle fossa, anterior incisural space, third cranial nerve, optic tract, ICA, anterior choroidal artery, PCoA, PCA, crural and ambient cisterns, and basal vein were exposed completely and preserved. The medial arachnoid membrane must be kept intact to avoid injury to the third cranial nerve, anterior choroidal artery, optic tract, and lateral midbrain. The extent of resection was limited laterally by the lateral wall of the temporal horn, superiorly by the superior wall of the temporal horn and thalamus, and medially and posteriorly by the crural and ambient cisterns and posterior border of the cerebral peduncle. Postoperative magnetic resonance images demonstrate total resection (Figures 4A, B).

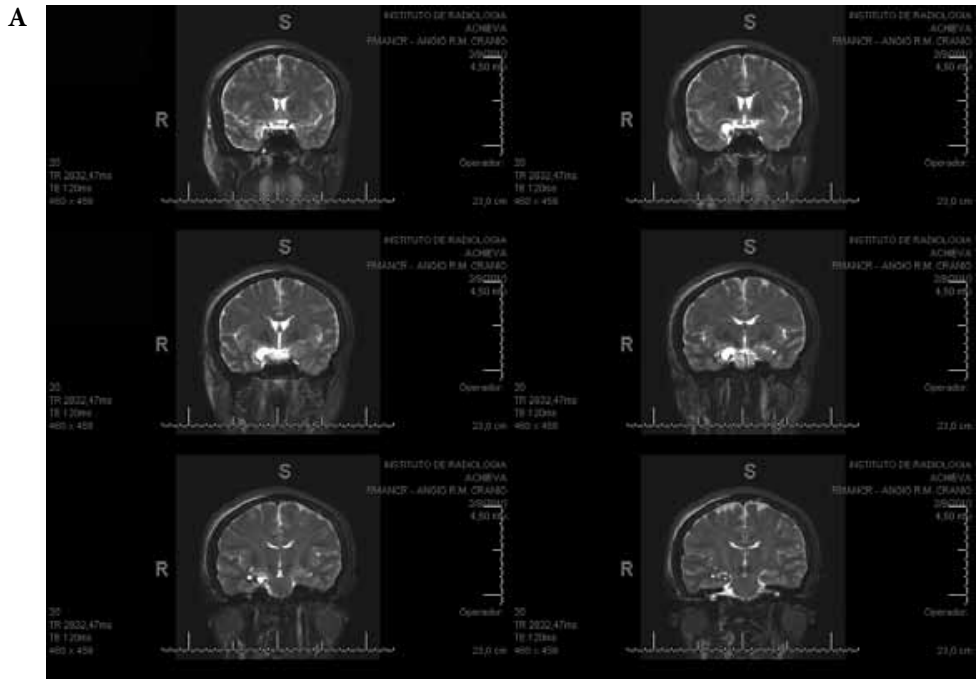

B

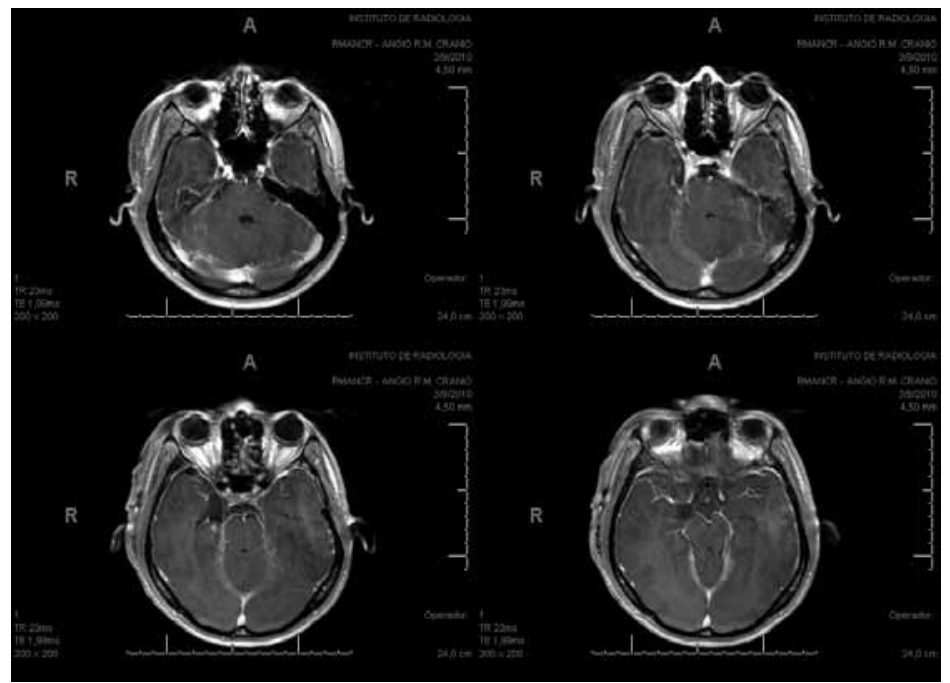

Figure 4 - (A) Postoperative T2-weighted MRI demonstrating removal of the uncus and part of the hippocampus. (B) Postoperative T1weighted MRI demonstrates removal of the part of the mesial temporal lobe. No cavernous malformation has been noticed. 


\section{Discussion}

Vascular injury is one of the most important complication associated with mesial temporal lobe operations. These injuries may result from retraction or inadvertent manipulation, caused mostly by insufficient exposure or late and poor visualization of these critical structure. ${ }^{7}$ Cautious must be exercised to identify vessels in the ambient cistern early enough to avoid damage. Because vital vascular and neural structures are initially spared by early identification and gentle dissection, this technique may help reduce the rate of surgical morbidity.

The next relevant problem is correct surgical orientation. ${ }^{10-16}$ Critical anatomical landmarks, including the uncus, head of the hippocampus, and lateral wall of the temporal horn, PCA, anterior choroidal artery, basal vein, and optic tract are readily recognized. The length of the surgical corridor has not been a drawback when we have used this anterior access technique to treat parasellar, middle fossa, and intrinsic midbrain lesions.

Surgical positioning, removal of the orbital rim, and drilling the sphenoid ridge are the main principles of this technique. Adequate positioning is crucial to displace the temporal lobe from the middle fossa to improve exposure. ${ }^{4-9}$ Removing the orbital rim ensures an ample range of movement for the surgical microscope, augments visualization, and improves surgical versatility. Finally, drilling the sphenoid ridge amplifies exposure near the area of interest, permitting increased visualization and manipulation..$^{4-9}$

\section{References}

1. Dare AO, Landi MK, Lopes DK, Grand W. Eyebrow incision for combined orbital osteotomy and supraorbital minicraniotomy: application to aneurysms of the anterior circulation. Technical note. J Neurosurg. 2001;95(4):714-8.

2. Cavalcanti DD, García-González U, Agrawal A, Crawford NR, Tavares PL, Spetzler RF, et al. Quantitative anatomic study of the transciliary supraorbital approach: benefits of additional orbital osteotomy? Neurosurgery. 2010;66(6 Suppl Operative):205-10.

3. Schwartz MS, Anderson GJ, Horgan MA, Kellogg JX, McMenomey SO, Delashaw JB Jr. Quantification of increased exposure resulting from orbital rim and orbitozygomatic osteotomy via the frontotemporal transsylvian approach. J Neurosurg. 1999;91(6):1020-6.

4. Figueiredo EG, Castillo De la Cruz M, Theodore N, Deshmukh P, Preul MC. Modified cervical laminoforaminotomy based on anatomic landmarks reduces need for bony removal. Minim Invasive Neurosurg. 2006;49(1):37-42.

5. Figueiredo EG, Deshmukh V, Nakaji P, Deshmukh P, Crusius MU, Crawford N, et al. An anatomical evaluation of the mini-supraorbital approach and comparison with standard craniotomies. Neurosurgery. 2006;59(4 Suppl 2):ONS212-20.

6. Figueiredo EG, Deshmukh P, Nakaji P, Crusius MU, Crawford $\mathrm{N}$, Spetzler RF, et al. The minipterional craniotomy: technical description and anatomic assessment. Neurosurgery. 2007;61(5 Suppl 2):256-64.

7. Figueiredo EG, Deshmukh $P$, Nakaji $P$, Crusius MU, Teixeira MJ, Spetzler RF, et al. Anterior selective amygdalohippocampectomy: technical description and microsurgical anatomy. Neurosurgery. 2010;66(3 Suppl Operative):45-53.

8. Figueiredo EG, Paiva WS, Gomes M, Castro Flores JA, Wen HT, Teixeira MJ. Modified abbreviated transcavernous approach to basilar artery aneurysms - case report. Surg Neurol. 2009;71(1):25-9.

9. Figueiredo EG, Deshmukh P, Zabramski JM, Preul MC, Crawford NR, Siwanuwatn R, et al. Quantitative anatomic study of three surgical approaches to the anterior communicating artery complex. Neurosurgery. 2005;56(2 Suppl):397-405.

10. Fries G, Perneczky A. Endoscope-assisted brain surgery: part 2 - analysis of 380 procedures. Neurosurgery. 1998;42(2):226-31.

11. Gonzalez LF, Crawford NR, Horgan MA, Deshmukh P, Zabramski JM, Spetzler RF. Working area and angle of attack in three cranial base approaches: pterional, orbitozygomatic, and maxillary extension of the orbitozygomatic approach. Neurosurgery. 2002;50(3):550-5.

12. Martellotta N, Gigante N, Toscano S, Maddalena GF, Tripodi M, Settembrini G, et al. Unilateral supraorbital keyhole approach in patients with middle cerebral artery (M1-M2 segment) symmetrical aneurysms. Minim Invasive Neurosurg. 2003;46(4):228-30.

13. Mitchell P, Vindlacheruvu RR, Mahmood K, Ashpole RD, Grivas A, Mendelow AD. Supraorbital eyebrow minicraniotomy for anterior circulation aneurysms. Surg Neurol. 2005;63(1):47-51.

14. Paladino J, Pirker N, Stimac D, Stern-Padovan R. Eyebrow keyhole approach in vascular neurosurgery. Minim Invasive Neurosurg. 1998;41(4):200-3.

15. Perneczky A, Fries G. Endoscope-assisted brain surgery: part 1 - evolution, basic concept, and current technique. Neurosurgery. 1998;42(2):219-24.

16. Perneczky A, Fries $\mathrm{G}$. Use of a new aneurysm clip with an inverted-spring mechanism to facilitate visual control during clip application. Technical note. J Neurosurg. 1995;82(5):898-9.

Correspondence address

Eberval G. Figueiredo

Rua Enéas C. Aguiar, 255

05403-000 - São Paulo, SP, Brazil 